\title{
Evolución constitucional peruana: de la Carta de 1979 a la Carta de 1993. Análisis crítico, perspectivas y debate sobre la actual reforma constitucional ${ }^{*}$
}

\author{
RONNY ROJAS ALVAREZ** \\ UNIVERSIDAD NACIONAL MAYOR DE SAN MARCOS
}

Resumen: A lo largo de la historia constitucional peruana, observamos la dación de 13 constituciones, de ideologías liberales - 1823, 1828, 1834, 1856 y 1867-; conservadoras - 1826, 1836, 1839 y 1860-; sociales - 1920, 1933 y 1979-; y la actual Carta neoliberal de 1993. Si bien las ideologías son diferentes, la situación es la misma: falta de vigencia de los textos constitucionales en la vida social, debido a las circunstancias coyunturales en las que surgieron éstas constituciones, esto es, que siempre han buscado cerrar una etapa política e inaugurar una nueva, usualmente autodenominada "revolucionaria".

Esta situación es expuesta en el presente trabajo, al remitirnos a la Constitución de 1979, que surge después de una época de dictadura militar, sus lineamientos principales son examinados debido a su importancia. Luego, exponemos el tránsito a la Carta de 1993, la situación constitucional actual, caracterizada por el debate en cuanto a la Reforma Constitucional, cuyas posiciones señalamos, indicando nuestro punto de vista.

Palabras Claves: Constitución, Reforma Constitucional, Constitución Peruana de 1979, Constitución Peruana de 1993.

Abstract: Across the Peruvian Constitutional history, we can observe the drafting of 13 constitutions of liberal ideologies - 1823, 1828, 1834, 1856 and 1867 -; conservatives - 1826, 1836, 1839 and 1860; socials - 1920, 1933 and 1979-; and the current neoliberal chart of 1993. Even though the ideologies are different, the situation is the same, the lack of force of the constitutional texts in the social life, due to the circumstances in which emerge these constitutions, this is, that always have search to close a political stage and inaugurate a new one, usually called "revolutionary"

This situation is exposed in the present work, refering to the Constitution of 1979, that surge after a time of military dictatorship, the main guidelines are analyzed because of their importance.

Then, we are going to expose the transition to the Chart of 1994, the actual constitutional situation, characterized by the debate of the constitutional reform, which positions we will show, indicating our own point of view.

Keywords: Constitution, Constitutional Reform, Peruvian Constitution of 1979, Peruvian Constitution of 1993.

\footnotetext{
* Versión escrita de la presentación realizada en el II Congreso Estudiantil de Derecho y Teoría Constitucional.

** Estudiante de la Facultad de Derecho y Ciencia Política de la Universidad Nacional Mayor de San Marcos, Lima, Perú.
} 


\section{Introducción}

La historia constitucional peruana ha sido pródiga en la expedición de constituciones; y en la incorporación nominal de diversas instituciones democráticas, pero no en la creación de una conciencia constitucional en la ciudadanía ni el pleno ejercicio del poder con lealtad constitucional de sus gobernantes.

El desfase de la falta de vigencia de los textos constitucionales en la vida social, se debe a que la expedición de constituciones se fueron dando al unísono de los cambios políticos y sociales de cada época ${ }^{1}$; como fue el caso del fin del Gobierno Militar; iniciada por Velasco Alvarado y continuada por Morales Bermúdez, o la transición del gobierno corrupto de Alberto Fujimori al de Alejandro Toledo.

Este curso histórico muestra que las constituciones y la vida constitucional han dependido directamente de los acontecimientos políticos y militares de cada época y que los operadores constitucionales no han sido capaces de procesar dichos fenómenos en el marco de la Constitución. Esto se debe a la falta de estabilidad política, que es expresión de la carencia de un consenso mínimo o pacto social siquiera entre las élites dirigentes para asegurara un Estado de Derecho duradero. Falta de acuerdo nacional que ha creado una cultura cívica de incredulidad de la sociedad respecto del Estado y de la Constitución, debido a que las necesidades y expectativas de la población no se han visto satisfechas por las corrientes ideológicas en cualquiera de sus constituciones: liberales, conservadoras, sociales, y la actual carta "neoliberal" de 1993.

Debido a ello, en el presente trabajo exponemos los Antecedentes y el Contexto donde surge la Carta de 1979, sus características básicas; la recepción que hace de los Derechos Humanos, destacando la importancia que se les otorga. Luego, se expone la trayectoria desde 1980 hasta la actualidad, con la inclusión de la Constitución de 1993, en el Gobierno Fujimorista, cuyas desventajas señalamos, frente al modelo impuesto por la Constitución de 1979.

En la actual situación; donde la falta de estabilidad política impide asegurar un Estado de Derecho duradero; donde se ha creado una cultura cívica de incredulidad en la Sociedad respecto del Estado y de la Constitución actual, se hace necesario reflexionar si es necesario una reforma a la carta actual, la vuelta a la carta de 1979, o la dación de una nueva Constitución, cuyo debate expondremos al final del trabajo, con la exposición de nuestra posición.

\section{La Constitución de 1979}

\section{Antecedentes}

En el tercer trimestre de 1968 se produce en el país una nueva interrupción constitucional en nuestra historia republicana mediante un golpe de Estado; como consecuencia; un gobierno formalmente democrático debió ceder paso ante un complot militar, de tendencia revolucionaria y metodología populista, que tuvo como objetivo "llevar a cabo profundas y urgentes reformas sociales que, reclamadas de antaño, no habían podido ser efectuadas por el gobierno formalmente democrático". ${ }^{2}$

Este gobierno formalmente ilegal, pero legitimado desde el inicio de sus primeras ocasiones, intentó profundas reformas sociales con diversa fortuna; variando la política de la nación, como señala

1 ALZAMORA Silva, Lizardo. La evolución política y constitucional del Perú independiente. Lima, 1942, p. 106

2 QUIROGA León, Aníbal. El módulo de la Constitución de 1979. En su: La Constitución: diez años después. Lima, ICS, 1989, p. 106 
el Dr. Bernales Ballesteros: "llama la atención que las fuerzas armadas (...); haya podido producir un proceso revolucionario de tanta trascendencia histórica (...)". ${ }^{3}$

La primera fase de este gobierno militar se desarrolla en casi siete años cruciales en la historia de la nación, caracterizados por una profunda catarsis política, social y económica. La gran oligarquía tradicional desaparece para dar paso a una incipiente burguesía nacional, y a una clase media; además de presentarse el fenómeno de la migración campesina; producto del centralismo y como efecto residual de la reforma agraria.

La segunda fase; iniciada en 1975, se dió cuando un movimiento institucional al interior del Sector Militar, dejó de lado al General Velasco y es reemplazado por el General Morales Bermúdez, este cambio se produce por diversos factores como los excesos cometidos al confiscar medios de comunicación social, la salud del Gral. Velasco, entre otros.

Morales Bermúdez; frente al rechazo popular del militarismo, concibe la entrega del poder a los civiles, iniciándose el proceso de conversión democrática del Estado Peruano. En octubre de 1977 se convoca a una Asamblea Constituyente, en Junio de 1978 se eligen a sus representantes; que durante un año trabajó el nuevo texto constitucional. Si bien el gobierno militar realizó algunas observaciones al Proyecto de Constitución ${ }^{4}$; éstas son rechazadas por la Asamblea.

En mayo de 1980; se producen las elecciones presidenciales; resultando ganador el Arquitecto Fernando Belaúnde Terry. Es con la asunción de mando del electo presidente; que la promulgación de la Carta se da de manera formal ${ }^{5}$. Así, el propio 28 de julio de 1980 se firma el cumplimiento de la Constitución Peruana, que cobrará vigor a partir del día siguiente de su publicación, según la formalidad de la temporalidad legislativa.

\section{Lineamientos de la Constitución de 1979}

Expondremos los principales lineamientos que surgieron de la Constitución Política de 1979:

a) Es un texto consensuado; para lo cual hubo acuerdo de intereses, antes que de ideologías. Esto se explica por la composición plural de la Asamblea Constituyente que redactó esta Constitución, y porque ninguna de las fuerzas políticas tenía una mayoría absoluta como para hacer primar sus decisiones. ${ }^{6}$

b) Existe una consagración del pluralismo, tanto económico como político. Económico pues se admitió variadas formas de propiedad, se consagró una economía social de mercado, se ratificó la intervención del Estado en la actividad económica, sin menoscabo de la libre iniciativa privada.

En lo político, porque se reconoció constitucionalmente y se le dio un status definido a los partidos políticos.

c) Hallamos un respeto y exaltación de los Derechos Humanos, como no lo hubo en anteriores textos constitucionales, motivado debido a la salida de un gobierno militar que no siempre respetó estos derechos y asimismo a la proyección internacional de los Derechos Humanos, con la Declaración Universal de los DDHH, en 1948; y sucesivos documentos internacionales.

\footnotetext{
${ }^{3}$ BERNALES Ballesteros, Enrique. Socialismo y Nación. Lima, Mesa Redonda Editores, 1987, p. 97-98.

${ }^{4}$ Se argumentaba un excedente en las funciones de la Asamblea, que debían restringirse a la dación de una nueva Carta Política en: PAREJA Paz, José. Derecho Constitucional Peruano y la Constitución de 1979. Lima, Valenzuela Editores, 1980. Tomo I, p. 242.

5 Pues ya la Asamblea Constituyente lo había promulgado el 12 de Julio de 1979

${ }^{6}$ GARCIA Belaúnde, Domingo. Esquema de la Constitución Peruana. Lima, 1981,p. 52
} 
d) Protección procesal de los Derechos Humanos; mediante las acciones de Hábeas Corpus y Amparo. Asimismo, se pudo acceder a la Jurisdicción Supranacional. ${ }^{7}$

e) La impronta antimilitar; pues hubo un rezago en la Constitución contra lo que es el militarismo y los gobierno de facto, en pro de la defensa de los gobiernos constitucionales.

f) Tendencia Reglamentarista; la Constitución de 1979 fue una de las más extensas del mundo con 307 artículos y 18 disposiciones generales y transitorias. La idea de la Asamblea Constituyente fue plasmar en la Carta todas las aspiraciones y las demandas del pueblo; pensamiento considerado como "un equivocado afán de creer que la simple previsión normativa conlleva a la garantía de un futuro estable y democrático". ${ }^{8}$

g) Definición explícita de que el Perú es un Estado Social y Democrático de Derecho;" ésta constitución postula un "Estado de Bienestar", muy marcado, de apoyo social y vocación asistencial en favor de los sectores menos favorecidos, expresándose en el reconocimiento de derechos como el acceso a la seguridad social y a la protección integral de la salud.

h) La configuración de nuevos órganos constitucionales; como el Consejo Nacional de la Magistratura, el Tribunal de Garantías constitucionales, el Ministerio Público (antes parte del Poder Judicial) y el Jurado Nacional de Elecciones.

\section{Tránsito de la Constitución de 1979 a la Constitución de 1993}

La Carta política de 1979 cerró el período del régimen militar populista, e inauguró en los años $80^{\prime}$ un amplio escenario democrático para la reflexión jurídica y política, por el establecimiento de un moderno diseño constitucional democrático y social, donde destacó la creación de la Jurisdicción Constitucional, la incorporación de los Derechos Humanos y la Jurisdicción Supranacional, las Garantías Constitucionales y el Tribunal de Garantías Constitucionales. ${ }^{10}$ Pero, paradóiicamente, en el marco de la democracia constitucional, también se dio inicio a la etapa de violencia política y crisis económica, que marcó el desarrollo de la constitución en la década de los ochenta y el funcionamiento de la justicia constitucional.

La violencia política se vio compulsada por el accionar terrorista de Sendero Luminoso y el MRTA, con el correspondiente reforzamiento del poder político de las Fuerzas Armadas, y la presencia de la hiperinflación, que paradójicamente fortaleció a los grupos de poder económicos.

\footnotetext{
Así vemos que son fines de éstas acciones: garantizar la primacía de la Constitución, es decir, la jerarquía formal de la Constitución y la vigencia de los derechos fundamentales; es decir, tienen una finalidad trascendente que los distingue de los demás procesos judiciales. La Supremacía Constitucional, recién se consigna en la Constitución de 1979. Cfr.: QUIROGA León, Aníbal. El módulo de la Constitución de 1979. En su: La Constitución: diez años después. Lima, ICS, 1989, p. 34.

8 QUIROGA León, Aníbal. El módulo de la Constitución de 1979. En su: La Constitución: diez años después. Lima, ICS, 1989, op. cit, p. 29.

Observamos una marcada influencia de la Constitución Alemana de Weimar de 1919, impulsada por Hugo Preuss y Max Weber. Esta carta trato de reordenar la Sociedad Alemana luego de la 1ra. Guerra Mundial. Se reemplazó al Estado Gendarme (Juez y Policía) del siglo XIX; con el Estado Social de Derecho; que garantiza un conjunto de derechos económicos, sociales y culturales. Se asigna un rol de promotor social al Estado (que capta y redistribuya la riqueza)

${ }^{10}$ GARCIA Belaúnde, Domingo., La Constitución en el Péndulo. Arequipa, UNSA, 1996., p. 26.
} 
Estos factores dan lugar a la progresiva institucionalización de las corrosivas prácticas gubernamentales, como son: el abuso de las emergencias constitucionales - económicas y político - militares, tomándose como justificación para cualquier exceso, la crisis del sistema político y económico, abriéndose una vez más, la brecha entre el texto constitucional y la realidad, poniendo en evidencia la débil vida constitucional y la precaria convicción democrática de los gobernantes del país.

Desde mediados de la década de los años 80', frente al escenario de crisis económica aparecieron críticos severos, que postulando la vuelta al liberalismo económico, plantearon refundar la legitimidad social ya no con el Estado Benefactor, sino en el seno de la sociedad y del mercado, ${ }^{11}$ en virtud del cual, el gobierno recién electo de Fujimori en 1990, promovió la incorporación del liberalismo económico, infringiendo sus promesas electorales.

Desde la prospectiva política de grave conflicto interno, creado por el accionar de los movimientos terroristas, las Fuerzas Armadas con el apoyo del nuevo gobierno y los grupos económicos, sostuvieron la necesidad de restaurar el orden civil y la seguridad ciudadana, para lo cual, mediante legislación delegada del Congreso al Ejecutivo, se reforzó el poder militar en la lucha contra el terrorismo.

Es así que el presidente hizo un uso y abuso de las facultades presidenciales extraordinarias para expedir decretos legislativos y decretos de urgencia, frente a los cual, se opuso el Congreso de entonces, motivando el autogolpe de Estado de Abril de 1992, bajo el argumento que entidades como el Congreso y el Tribunal de Garantías Constitucionales, eran un obstáculo para la modernización y el progreso del país.

Así, con el apoyo de las fuerzas armadas, se clausuró el Congreso, se destituyó a los vocales de la Corte Suprema y se clausuró el tribunal de Garantías Constitucionales, Se instaba la arbitrariedad en el ámbito de la actividad estatal, afectando los derechos y libertades de los ciudadanos, estableciéndose un Estado de la Fuerza por el cual la autoridad somete a la ley.

\section{La Constitución de 1993}

El régimen de facto pronto sintió la presión política internacional que suspendió y cortó la ayuda económica y financiera necesaria para la implementación de su programa económico, motivo por el cual, tuvo que someter a la voluntad popular un proyecto de retorno a la democracia, mediante la convocatoria a elecciones generales para un Congreso Constituyente y elecciones para renovar a los gobiernos locales, más no para nuevas elecciones presidenciales, sino hasta 1995.

En este accidentado proceso de retorno a la democracia, el gobierno de facto no se replanteó reconstruir el consenso quebrado con la medida inconstitucional, sino insistir en el proyecto político y económico, con la autosuficencia del apoyo de los poderes fácticos y privados, en particular de las fuerzas Armadas, los medios de comunicación, los grupos empresariales y el apoyo popular obtenido en elecciones para el CCD no siempre de transparentes resultados, quienes anteponiendo sus intereses a los de la Constitución, configuraron un retorno constitucional mediocre. ${ }^{12}$

Sin embargo, el gobierno obtuvo notoria legitimidad social debido a la captura del líder máximo de Sendero Luminoso entre otros y al control de la hiperinflación. A base de estos logros en lo político y económico, la sociedad obtuvo una expectativa de paz civil, en virtud de la cual el gobierno hizo escarmiento de las instituciones democrático-representativas, en particular de los partidos políticos y del Poder Judicial, como, por otro lado, utilizó a este último como un instrumento de control y desviación de las demandas ciudadanas en defensa de sus derechos fundamentales y del Estado de Derecho.

${ }^{11}$ DE SOTO, Hernando. El otro Sendero. Lima, Instituto Libertad y Democracia, 1986, p. 16.

${ }^{12}$ GARCÍA Belaúnde, Domingo, La Constitución Traicionada. Lima, Segiusa, 1993, p. 83 
Siguiendo las huellas del inestable derrotero constitucional peruano, el Congreso Constituyente Democrático aprobó un nuevo texto constitucional que entró en vigencia el 30 de Diciembre de 1993, el mismo que significó, por un lado, una respuesta política al Estado social de la Constitución de 1979, al cual el gobierno atribuyó un rol obstruccionista a las medidas de modernización en función de la economía libre de mercado, otorgando asidero a un pretendido pensamiento neoliberal, que cerró con la etapa del constitucionalismo social más nominal que real, y; por otro lado, constituyó una salida política frente a la presión política interna y sobretodo económica internacional producida a raíz del autogolpe de Estado de Fujimori de 1992.

En tal sentido, el esquema constitucional de 1993 expresa jurídicamente el programa político y sobre todo el programa económico del gobierno, de servir de carta de garantía para los inversionistas a través de la consagración de una constitución económica de mercado y de la eliminación de la planificación democrática o concertada, libre de los atavismos empresariales estatales y del control de precios, defensora de la propiedad privada sin posibilidad de la expropiación por interés social y la exclusión del tratamiento preferencial de ciertos sectores sociales y económicos marginados. En ese sentido. "Constitución puede ser calificada como de un liberalismo social moderno, que intenta insertarse en una economía internacional de mercado (...)". 13

Se puede afirmar que la Constitución refuerza el régimen presidencialista, a través de la figura de la reelección presidencial inmediata y el debilitamiento del Congreso convertido en unicameral y con algunas competencias reducidas ${ }^{14}$. También extiende el poder militar para juzgar los delitos de terrorismo y condenarlos a la pena de muerte y, reduce los ingresos y las competencias de los gobiernos descentralizados. Asimismo, el texto constitucional redimensiona nominalmente el sistema judicial existente, ampliando las competencias del Tribunal Constitucional, creando la Defensoría del Pueblo, otorgándole al Jurado Nacional de Elecciones carácter de máximo organismo en materia jurisdiccional electoral, despolitizando la elección de los vocales de la Corte Suprema de Justicia, mediante su nombramiento por un organismo técnico como el Consejo Nacional de la Magistratura. Así se convierte la Constitución en un simple instrumento para la consagración de los cambiantes objetivos políticos y económicos de los poderes fácticos y privados.

Por ello, será otro el escenario gubernamental privilegiado; el de la comunicación pública del Presidente Fujimori y el pueblo, en virtud de lo cual el poder de los medios de comunicación privados adquiere un valor político concreto para el régimen hasta el punto de llegar a una dependencia absoluta de los medios de comunicación.

Un caso paradigmático del despego gubernamental al constitucionalismo se produjo al cumplirse el primer año de gobierno del reelecto Presidente Fujimori, cuando la mayoría parlamentaria oficialista, aprobó el 23 de agosto del 1996, la Ley No 26657, que la denominó Ley de Interpretación Auténtica del Art. $112^{\circ}$ de la Constitución. Esta ley-medida, llamada de interpretación auténtica del $112^{\circ}$ de la Constitución, habilitaba al entonces Presidente Fujimori para que pueda ser reelecto en las elecciones políticas generales del año 2000.

Esta ley fue declarada inconstitucional por el Tribunal Constitucional, dando lugar a la acusación constitucional que formuló la mayoría parlamentaria oficialista contra los magistrados constitucionales que firmaron la resolución que declaró inaplicables la ley de la reelección presidencial. Proceso político que sin respetar las garantías del debido proceso parlamentario concluyó arbitrariamente en mayo de 1997 con la destitución de tres magistrados constitucionales.

En adelante la Constitución y las instituciones propias de la democracia representativa como el Congreso, el Poder Judicial, el Tribunal Constitucional, la Contraloría General, los gobiernos locales,

\footnotetext{
13 TORRES y Torres Lara, Carlos. Alcances de la nueva Constitución del Perú. Ius et praxis. (25), p. 48.

${ }^{14}$ FERRERO Costa, Raúl. Secuestro y Rescate de la Democracia. Lima, Fondo de Cultura Económica, 2001 p. 255.
} 
entre otros organismos constitucionales, quedaron a merced plenamente del gobierno, y su proyecto re - eleccionista. Eso se puso de manifiesto con las elecciones presidenciales y parlamentarias del año 2000. En efecto, en dicho proceso electoral no se cumplieron los estándares mínimos de una elección democrática.

La fraudulenta victoria de Fujimori sobre el candidato Alejandro Toledo en la segunda vuelta electoral desencadenó una ola de protestas ciudadanas de la oposición política y social, así como también, dio lugar al cuestionamiento internacional a la legitimidad del tercer mandato.

\section{Transición a la democracia y situación actual}

Dada la crisis de legitimidad política que generó el proceso de re-reelección presidencial de Fujimori, la Organización de los Estados Americanos (OEA) en junio del 2000 sentó en el banquillo de los acusados al gobierno de Fujimori por violar los mandatos de defensa del sistema democrático de la carta americana. En ese sentido, la OEA estableció en Lima en julio del 2000, una mesa de Diálogo donde representantes del gobierno, la oposición y de la sociedad civil, debían debatir sobre temas centrales para el fortalecimiento democrático, la reforma del sistema judicial, la reforma de sistema electoral, la reforma del aparato militar y, la restitución de los medios de comunicación a sus legítimos propietarios básicamente.

En el mes de setiembre, en pleno proceso de diálogo, apareció un video en los medios de comunicación social, donde Vladimiro Montesinos, hombre fuerte del régimen Fujimorista, entregaba quince mil dólares al Congresista de oposición Kouri para que pase a la bancada parlamentaria fujimorista, a fin de lograr la mayoría parlamentaria.

Frente a esta situación, el Presidente Fujimori en vez de destituir y mandar procesar a su asesor Montesinos y pedir que se levante la inmunidad parlamentaria del congresista Kouri, anunció su renuncia a terminar su mandato el 2005, disponiendo la convocatoria a elecciones no sólo presidenciales, sino también parlamentarias.

En consecuencia, el 5 de noviembre del 2000 entró en vigencia la Ley $\mathrm{N}^{\circ} 27365$ mediante la cual se realizó la tercera reforma constitucional a la Constitución de 1993, con el fin de permitir que los mandatos de cinco años del entonces Presidente Fujimori y de los parlamentarios, culminen en julio del 2001, en vez de terminar en julio del 2005. Asimismo, se dispuso la prohibición de la reelección presidencial inmediata, salvo que se deje un período como mínimo.

Asimismo, se produjo otro hecho sin precedentes políticos, la salida de Fujimori del Perú so pretexto de participar en Brunei en una conferencia internacional de economía de la región Asia-Pacífico; para luego, continuar viaje extra-oficialmente al Japón, país desde el cual envió su carta de renuncia a la Presidencia de la República. El 22 de noviembre del 2000 el Congreso de la República aprobó declarar la vacancia presidencial por causa de permanente incapacidad moral, rechazando su pedido de renuncia, de conformidad con el Artículo $1213^{\circ}$-2 de la Constitución.

La declaración de la incapacidad moral de Alberto Fujimori tuvo como consecuencia constitucional inmediata su destitución como Presidente de la República; es decir que, quedó vacante el cargo de jefe de Estado y jefe de gobierno que asume el Presidente de la República, de conformidad con los artículos $110^{\circ}$ y $118^{\circ}, 3$ de la Constitución, Si bien, en el régimen constitucional peruano existen dos vice-presidentes de la República, para reemplazar sucesivamente al Presidente en caso de ausencia, suspensión o vacancia, éstos renunciaron previamente a la destitución presidencial dada la grave crisis en la que estaban directamente involucrados Fujimori y Montesinos.

Producida la vacancia presidencial de Fujimori el Dr. Valentín Paniagua como Presidente del Congreso, asumió automáticamente el cargo provisorio como Presidente de la República, de confor- 
midad con el Artículo $115^{\circ}$ de la Constitución. Valentín Paniagua ejerce las competencias y facultades del cargo de la Presidencia de la República de pleno derecho, hasta el 28 de julio del 2001, fecha en la cual se llevará a cabo el relevo de la Presidencia, ante el nuevo Congreso que salió electo en las elecciones políticas generales del 8 de abril del 2001.

El gobierno democrático del Presidente Toledo, iniciado el 28 de Julio del 2001, actualmente se encuentra deslegitimado, como reflejan las encuestas, así como también las Instituciones Públicas. Es en este contexto que se propone una reforma constitucional, cuyo debate veremos a continuación.

\section{El debate constitucional}

La discusión en torno a la situación jurídico - política de la Constitución de 1993; ha sido tratada por la Comisión de las Bases de una Reforma Constitucional, la cual considera tres caminos:

- Primero: declarar la nulidad de la Carta de 1993, pero convalidando todos sus actos aunque dejándolos sujetos a revisión futura, para retornar a la vigencia de la Constitución de 1979.

- Segundo: reformar la Constitución de 1979, adaptándola a los tiempos modernos, y reconociendo instituciones novedosas y que funcionan -como la Defensoría del Puebloasí como los Tratados Sobre Derechos Humanos y demás normas que garanticen la estabilidad política y jurídica.

- La tercera posibilidad consiste en convocar a un referéndum para que el pueblo decida volver a la Carta de 1979 o encomendar la elaboración de una nueva Constitución., y entonces se convoque a una Asamblea Constituyente.

La corriente que propugna la vuelta en vigencia de la Carta de 1979, se basa en las siguientes razones:

- La Constitución de 1979 establece que no pierde su validez y vigencia por actos de fuerza, o los que no se sustentan en la soberanía del pueblo. Por eso, desde un punto de vista constitucional, retornar a la Carta de 1979 sería lo prudente de acuerdo con la Historia, la Política, y el Derecho. Además, una vez recuperado su imperio, es un camino para consolidar, a través de las fuerzas políticas, un pacto en torno a la Constitución.

- La necesidad de someter a la Carta de 1979 a un procedimiento de reforma para incorporar las nuevas instituciones aparecidas en la Carta de 1993, significa desconocer la existencia de un bloque de la constitucionalidad; es decir, concebir que la Constitución no se agota en un código, que los tratados sobre derechos humanos así como las normas que regulan instituciones para su defensa y protección también forman parte de ella.

La otra corriente, con la cual estamos de acuerdo, plantea la dación de una nueva Constitución, que obedezca a la voluntad general ciudadana de romper con el sistema de gobierno autocrático y corrupto que se implementó durante la década pasada, bajo el régimen del ex-Presidente Fujimori; que contemple cuatro propuestas concretas:

1. Proclamación en la nueva Carta, de los derechos fundamentales mejor dicho, una restitución de los derechos extirpados por la Constitución de 1993. 
La nueva Constitución debe de reconocer la garantía y la exigibilidad de ambos tipos de derechos, el Estado debe dejar de poner pretextos para justificar su desconocimiento, teniendo en cuenta que en vez de poner trabas al respecto, debe de reflexionar y tomar medidas, en cuanto a los elevados sueldos burocráticos, que junto con el pago de la Deuda Externa, consumen gran parte del Presupuesto Nacional.

2. Un segundo frente del debate es el referido a las características de los derechos fundamentales. La presencia de una sociedad civil más amplia y diversa ha llevado a la incorporación de derechos "nuevos" entre los cuales están el derecho a un medio ambiente adecuado. También están los derechos de participación de las diversas culturas del país en la vida nacional o los relativos a la igualdad de oportunidades en la participación política,

También debemos destacar el derecho a la participación en las decisiones del Estado. La discusión sobre cuán fundamentales son los nuevos derechos y qué atención merecen por la sociedad y el Estado debe de ser debatido.

3. El tercer aspecto se refiere al Régimen económico. En este aspecto, la nueva Constitución debe de contar con una base social y económica, que se exprese en la necesidad de establecer un sistema de protección y desarrollo de los derechos fundamentales; en tanto que la persona es el fin supremo de la sociedad, el Estado y la Empresa; así como permitir el control y la descentralización económica; a fin de crear las condiciones mínimas para el bienestar socio - económico; que aseguren una justa y eficiente distribución de la riqueza.

4. El cuarto aspecto socioeconómico es la presencia de las reivindicaciones descentralistas en el debate nacional, como las competencias y la autoridad económica de los futuros gobiernos regionales.

Estos lineamientos, deben de ser tomados en cuenta en la dación de la nueva constitución, que se centre en la persona humana, en el respeto de sus derechos fundamentales, en un ámbito democrático, donde prime un Estado de Derecho.

\section{Conclusiones}

- En nuestro desarrollo constitucional, se presenta una tendencia imitativa, debido a una falta de originalidad. Asimismo un desfase entre el texto normativo y las realidades a las cuales este se aplica.

También observamos la tendencia a acentuar el predominio del Poder Ejecutivo; paralelo a la existencia de un Congreso débil; cuyo rol se ha limitado muchas veces a servir de caja de resonancia del Ejecutivo.

Existe también una tendencia al continuismo, que se expresa en la reiterada presencia de las mismas figuras políticas, tanto a nivel del Parlamento como el Presidencial.

- Las Constituciones que se fueron dando, siempre han buscado cerrar una etapa política e inaugurar una nueva; autodenominada "Revolucionaria". Sin embargo, en el Perú, las quiméricas ideologías políticas liberal, conservadora y social; han tenido un asidero apenas virtual en la vida social y el quehacer jurídico, produciendo constituciones nominales que no concuer- 
dan con los presupuestos sociales y económicos, o en todo caso, constituciones semánticas en beneficio de los que detentan el poder.

- De nada serviría una nueva Constitución; si no se respeta y se cumple, al igual que las leyes; debido a que en nuestro país una de las características más notorias es nuestra falta de respeto por la Ley y el orden Constitucional. Si el Perú es un modelo ideal de Leyes: pues hay leyes para todo, solo falta una que mande que se cumplan todas las demás. Los regímenes democráticos que se han sucedido desde 1940 a la fecha - bajo la vigencia de tres constituciones -, nos presentan un Estado de Derecho de apariencia o formal, pero nunca un Estado de Derecho sustancial o de fondo, donde impere la seguridad jurídica y el respeto por la ley.

- En los siglos XVIII, XIX y comienzos del siglo XX se tenía la concepción de la Constitución como una "Norma Normada"; como una "Norma Jurídica". Después de la II Guerra Mundial y con la Declaración Universal de los Derechos Humanos de 1948, es que se da plena valoración a la dignidad de la persona humana. Es por ello, que la Constitución ahora es vista como un Código de Valores; el hombre pasa a ser sujeto de derecho internacional, en cuanto a la Legislación Supranacional.

- La Constitución de 1979 otorgaba rango constitucional a las normas sobre derechos humanos contenidas en tratados internacionales, pero en la Carta de 1993, se suprimió de manera expresa esta referencia, con la intención de desvincularse del cumplimiento de estas normas y de la competencia contenciosa de la Corte Interamericana.

Actualmente los tratados sobre derechos humanos tienen una jerarquía supralegal, es decir de carácter constitucional ${ }^{15}$. Por ello conforme a lo señalado por la Convención de Viena, no cabe alegar normas de Derechos Internacionales para desentenderse de las obligaciones internacionales asumidas. ${ }^{16}$.

Por ello al interpretarse los derechos constitucionales debe hacerse de conformidad con los tratados sobre derechos humanos y constituyen principios rectores que deben orientar la interpretación constitucional que se realice tanto en sede judicial como en el Tribunal Constitucional.

La vigencia afectiva de los derechos constitucionales; significa reconocer la primacía de los derechos fundamentales, de parte del Estado, en cuanto estos derechos son anteriores y superiores al Estado ${ }^{17}$; en virtud de los pactos y tratados internacionales, por ello estos derechos requieren de una promoción permanente.

\section{Referencias Bibliográficas}

ALZAMORA Silva, Lizardo. La evolución política y constitucional del Perú independiente. Lima, 1942. 205 p.

BERNALES Ballesteros, Enrique. Socialismo y Nación. Lima, Mesa Redonda Editores, 1987. 349

p.

DE SOTO, Hernando. El otro Sendero. Lima, Instituto Libertad y Democracia, 1986. 286 p.

FERRERO Costa, Raúl. Secuestro y Rescate de la Democracia. Lima, Fondo de Cultura Económica, 2001. 709 p.

GARCIA Belaúnde, Domingo. Esquema de la Constitución Peruana. Lima, 1981. 250 p.

${ }^{15}$ NOVAK, Fabián y Salmón, Elizabeth. Las Obligaciones Internacionales del Perú en Materia de Derechos Humanos. Lima, Fondo Editorial PUCP, 2002, p. 114.

${ }^{16}$ MONROY Cabra, M.G., Derecho de los Tratados. Bogotá, Temis,1978.. p. 82.

${ }^{17}$ LOCKE, Jhon. Segundo Tratado sobre el Gobierno Civil. México, Fondo de CulturaEconómica,1960,p.106. 
La Constitución en el Péndulo. Arequipa, UNSA, 1996. 200 p.

La Constitución Traicionada. Lima, Segiusa, 1993. 216 p.

LOCKE, Jhon. Segundo Tratado sobre el Gobierno Civil. México, Fondo de Cultura Económica,1960. 209 p.

MONROY Cabra, M.G., Derecho de los Tratados. Bogotá, Temis,1978.

NOVAK, Fabián y Salmón, Elizabeth. Las Obligaciones Internacionales del Perú en Materia de Derechos Humanos. Lima, Fondo Editorial PUCP, 2002. 800 p.

PAREJA Paz, José. Derecho Constitucional Peruano y la Constitución de 1979. Lima, Valenzuela Editores, 1980. Tomo I. 400 p.

QUIROGA León, Aníbal. El módulo de la Constitución de 1979. En su: La Constitución: diez años después. Lima, ICS, 1989. pp. 106 - 128. 316 p.

TORRES y Torres Lara, Carlos. Alcances de la nueva Constitución del Perú. Ius et praxis. (25): 48-61, 1995. 